\title{
Transvaginal ultrasound compared with serum $\beta$-hCG level for diagnosis of ectopic pregnancy in symptomatic patients
}

\author{
Somayeh Zeynizadeh Jeddi ${ }^{1}$, Noushin Mobaraki ${ }^{2 *}$, Akbar Pirzadeh $^{3}$
}

\author{
${ }^{1}$ Department of Radiology, School of Medicine, Ardabil University of Medical Science, Ardabil, Iran \\ ${ }^{2}$ Department of Obstetrics and Gynaecology, School of Medicine, Ardabil University of Medical Science, Ardabil, Iran \\ ${ }^{3}$ Department of Otorhinolaryngology, Fatemi Hospital, Ardabil University of Medical Sciences, Ardabil, Iran
}

Received: 12 January 2020

Revised: 30 January 2020

Accepted: 05 February 2020

\section{*Correspondence:}

Dr. Noushin Mobaraki,

E-mail: n.mobaraki@arums.ac.ir

Copyright: (C) the author(s), publisher and licensee Medip Academy. This is an open-access article distributed under the terms of the Creative Commons Attribution Non-Commercial License, which permits unrestricted non-commercial use, distribution, and reproduction in any medium, provided the original work is properly cited.

\begin{abstract}
Background: Ultrasonography (US) is the most important imaging modality in detecting both intrauterine and ectopic pregnancies. The aim of this study was to comparison transvaginal ultrasound with serum $\beta$-hCG level for diagnosis of ectopic pregnancy (Ep) in referred women to Ardabil city hospital.

Methods: In this cross-sectional study, a total of 207 women with diagnosis of Ep were enrolled during 2018. All women underwent transvaginal US in the first 24 hours and US done by an expert radiologist. Serum levels of $\beta$-hCG at first 24 hours and the time gap between US examination and last menstrual period (LMP) were compared between women with positive and negative US findings. Data collected by a checklist and analyzed by statistical method in SPSS version 21.

Results: The primary US were positive in 174 women $(84.1 \%)$ and negative in 33 women (15.9\%). The mean of time gap between US and LMP in women with diagnosed EP was significantly higher than other women (median, 42 days versus 45 days, $\mathrm{p}=0.042$ ). Also, the mean of serum level of $\beta$-hCG had significant difference between two groups. In logistic regression analysis results showed that the time gap between US and LMP hadn't significant impact on EP diagnosis. The best discriminative zone was set at a serum $\beta$-hCG level of $105.65 \mathrm{mIU} / \mathrm{ml}$ with a sensitivity and specificity of $82 \%$ and $27 \%$, respectively and the under-ROC area was $58 \%$.

Conclusions: According to our findings, the median serum level of $\beta$-hCG in women with undiagnosed Ep were significantly lower than women with correct diagnosis of Ep but the mean and median of time gap between US and LMP in women with diagnosed EP was more than women without Ep. Also, the proposed discriminative zone for serum level of $\beta$-hCG in our study is different from the previous studies.
\end{abstract}

Keywords: $\beta$ - hCG discriminatory zone, Ectopic pregnancy, Transvaginal ultrasound

\section{INTRODUCTION}

Ectopic pregnancy (EP) accounts for $2.8 \%$ of pregnancies and $15 \%$ of causes of pregnancy related death. ${ }^{1}$ Most of EP $(95 \%)$ occur in fallopian tubes. All patients with a positive pregnancy test (serum B. HCG), vaginal bleeding, pelvic pain and adnexal masses should be considered at risk of ectopic pregnancy. Completely reliable diagnosis of ectopic pregnancy is only when a live embryo or pregnancy bag containing a pregnancy bag is found in an ectopic position (18-26\% of EP). ${ }^{2}$ Despite clinical signs, early ultrasound scanning of the first trimester should be aimed at detecting the location of the gestational sac. In the early stages of intrauterine pregnancy, incomplete abortion and ectopic pregnancy, the gestational sac is not always detectable. ${ }^{1}$ In the 
absence of specific sonographic findings, the possibility of ectopic pregnancy can be predicted by identifying nonspecific sonographic findings and consistent with the discriminatory serum B. HCG level. ${ }^{3,4}$ The risks associated with ectopic pregnancy and the women's pregnancy status, determine the need for surgical or reultrasound interventions and conservative treatment. ${ }^{1}$ One of the important differential diagnoses of EP in patients with positive B.HCG and abdominal pain and vaginal bleeding, is weak or aborted intrauterine pregnancy. Therefore, determination of B. HCG threshold level which can be more confidently rejected if EP ultrasound findings are negative and other diagnoses such as abortion is more important. Because EP and abortion require to different treatments and failure to true diagnosis of EP in a timely manner may increase mortality and morbidity in pregnant women. In addition to the development of ultrasound during this time and challenging the hCG- $\beta$ threshold level, the aim of this study was to compare the results of transvaginal ultrasound with BHC-G serum level in the diagnosis of ectopic pregnancy in pregnant women.

\section{METHODS}

This retrospective cross-sectional study was performed on the records of patients admitted to Alavi hospital with a diagnosis of EP in 2018. The sample were subjected to vaginal ultrasound for 24 hours with volusan E6 and all of them had serum levels of $\beta$-hCG measured by Elfa using a Minividas device in hospital laboratory. The diagnosis of EP in these patients was serial ultrasounds, laparoscopic or surgical methods. Finally based on inclusion and exclusion criteria, 207 patients with ectopic pregnancy were studied. Primary ultrasound results in ectopic pregnancy were compared with $\beta$-hCG levels in both groups with correct and incorrect diagnosis of transvaginal ultrasound. Patients who were unable to undergo vaginal ultrasound within 24 hours of receiving or not receiving $\beta$-hCG measurements were excluded during the study. Information gathered by using checklist containing age, duration of hospitalization, number of pregnancies and number of previous abortions, EP history, history of previous pelvic surgeries, hemoglobin level, patient LMP, contraceptive methods, endometrial thickness, volume pregnancy outcome, EP ultrasonographic view, EP side and amount of free fluid leading to surgery and heterotopic pregnancy were collected for the studied samples.

\section{Statistical analysis}

Collected data were analyzed using descriptive statistics in the form of medians, average, standard deviation, frequency and percentage and independent t-test for comparison between quantitative variables and chi-square or Fisher exact test for comparing qualitative data between two groups in SPSS version 21. The ROC curve was plotted to determine the appropriate cut off point for $\beta$-hCG surface. Correlation between variables was evaluated by Spearman coefficient. Logistic regression was used for multivariate modeling. $\mathrm{p}$ values less than 0.05 were considered statistically significant.

\section{RESULTS}

Of the 207 pregnant women with ectopic pregnancy, 174 $(84.1 \%)$ were diagnosed by primary transvaginal ultrasound and $33(15.9 \%)$ were not. The median age in the group diagnosed with EP was 31 (range: 1-76). According to the results of the U-man-Whitney test, there wasn't significant difference in age between two groups. The mean number of deliveries in the group diagnosed with EP was three times (range: 0-9) and there was no significant difference between two groups (Table 1).

The results of LMP interval and serum $\beta$-hCG levels are presented in Table 2. The average LMP interval in the group with no EP diagnosed with $38.84 \pm 18.2$ was significantly lower than that with the EP diagnosed with 47.2 \pm 19.9 (Table 2).

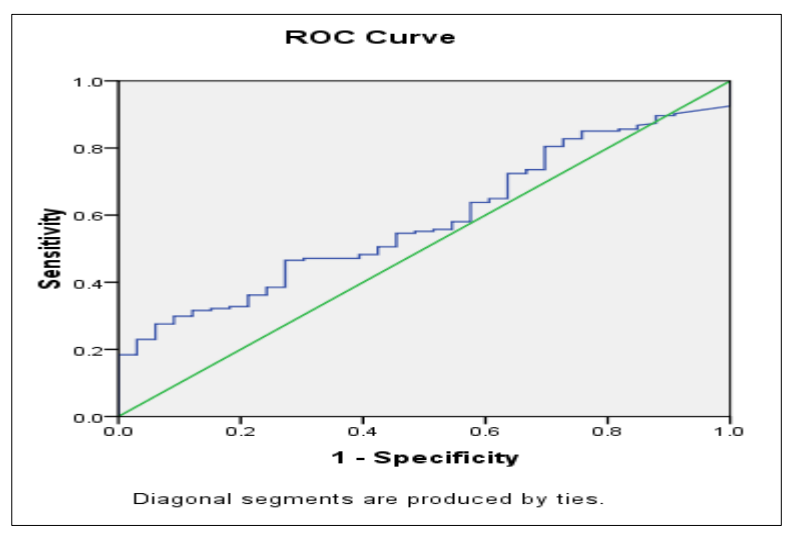

Figure 1: ROC curve for $\boldsymbol{\beta}$-hCG level in distinguish the positive and negative result of transvaginal sonography.

A total $8(4.6 \%)$ patients with EP had heterotopic pregnancy. There was a history of pelvic surgery in $66(37.9 \%)$ of the group with EP and $12(36.4 \%)$ of the group with no EP. Symptoms were in 162 patients (93.1\%) the group diagnosed with EP and 31(93.9\%) the group not diagnosed with EP but the difference between the two groups was not significant in terms of heterotopic pregnancy, history of pelvic surgery and symptoms. Abdominal pain was the most common symptom in both groups with and without EP with $61.5 \%$ and $63.6 \%$, respectively but the difference between the two groups was not significant (Table 3).

According to Spearman test, there was no significant correlation between two variables of serum $\beta$-hCG level and the time interval between sonography and LMP (rho=0.14 and $\mathrm{p}=0.08$ ). Based on the results of logistic regression model, variable time interval of ultrasound from LMP ( $\mathrm{p}=0.022)$ was significantly and independently associated with incorrect diagnosis by transvaginal 
ultrasound but there was no relationship between serum $\beta$-hCG levels with EP diagnosis. The highest sonographic profile of EP in the diagnosed group was adnexal mass with $93.7 \%$ (Table 4 ). The best cut off point for $\beta$-hCG was $105.65 \mathrm{mmol} / \mathrm{ml}$ with $83 \%$ sensitivity, $27 \%$ specificity and $58 \%$ the area under roc curve (Figure 1).

Table 1: Demographic characteristics of patients by EP status.

\begin{tabular}{|c|c|c|c|c|c|c|c|}
\hline \multirow{2}{*}{\multicolumn{3}{|c|}{ Variables }} & \multicolumn{2}{|c|}{ Undiagnosed EP } & \multicolumn{2}{|c|}{ Diagnosed EP } & \multirow[t]{2}{*}{ p-valuc } \\
\hline & & & $\mathbf{n}$ & $\%$ & $\mathbf{n}$ & $\%$ & \\
\hline \multirow{3}{*}{ Age } & $<20$ & & 16 & 9.2 & 5 & 15.2 & \multirow{3}{*}{0.57} \\
\hline & $21-35$ & & 121 & 69.5 & 22 & 66.7 & \\
\hline & $>35$ & & 37 & 21.3 & 6 & 18.2 & \\
\hline \multirow{4}{*}{$\begin{array}{l}\text { Number of } \\
\text { children }\end{array}$} & 0 & & 58 & 33.3 & 14 & 42.4 & \multirow{4}{*}{0.62} \\
\hline & 1 & & 53 & 30.5 & 10 & 30.3 & \\
\hline & 2 & & 59 & 33.9 & 9 & 27.3 & \\
\hline & 3 & & 4 & 2.3 & 0 & 0 & \\
\hline \multirow{5}{*}{$\begin{array}{l}\text { Previous } \\
\text { abortion }\end{array}$} & 0 & & 114 & 65.5 & 23 & 69.7 & \multirow{5}{*}{0.34} \\
\hline & 1 & & 43 & 24.7 & 5 & 15.2 & \\
\hline & 2 & & 9 & 5.2 & 4 & 12.1 & \\
\hline & 3 & & 3 & 1.7 & 1 & 3 & \\
\hline & 4 & & 5 & 2.9 & 0 & 0 & \\
\hline \multirow{2}{*}{\multicolumn{2}{|c|}{ Previous EP }} & Yes & 22 & 12.6 & 2 & 6.1 & \multirow{2}{*}{0.38} \\
\hline & & No & 152 & 87.4 & 31 & 93.9 & \\
\hline \multirow{2}{*}{\multicolumn{2}{|c|}{ Using contraceptive method }} & Yes & 4 & 2.3 & 1 & 3 & \multirow{2}{*}{0.58} \\
\hline & & no & 170 & 97.7 & 32 & 97 & \\
\hline \multirow{2}{*}{\multicolumn{2}{|c|}{ History of pelvic surgery }} & - & 108 & 62.1 & 21 & 63.6 & \multirow{2}{*}{0.8} \\
\hline & & + & 66 & 37.9 & 12 & 36.4 & \\
\hline \multicolumn{3}{|l|}{$\mathrm{Hb}$} & \multicolumn{2}{|c|}{$12.2 \pm 1.6$} & \multicolumn{2}{|c|}{$12.8 \pm 1.2$} & 0.07 \\
\hline \multicolumn{3}{|c|}{ Length of hospitalization } & \multicolumn{2}{|c|}{$4.3 \pm 2.8$} & \multicolumn{2}{|c|}{$5.3 \pm 3.3$} & 0.13 \\
\hline
\end{tabular}

Table 2. Information about US by EP status.

\begin{tabular}{|c|c|c|c|c|}
\hline Variables & & Undiagnosed EP & Diagnosed EP & p-value \\
\hline \multirow{4}{*}{ Time from LMP } & Median & 42 & 45 & \multirow{4}{*}{0.042} \\
\hline & Min & 1 & 13 & \\
\hline & Max & 76 & 102 & \\
\hline & Mean \pm SD & $38.84 \pm 18.2$ & $47.2 \pm 19.9$ & \\
\hline \multirow{4}{*}{$\beta$-hCG level } & Median & 873 & 1122.5 & \multirow{4}{*}{0.001} \\
\hline & Min & 2 & 0.2 & \\
\hline & Max & 49000 & 9900 & \\
\hline & Mean \pm SD & $1199.9 \pm 1270.1$ & $4633.4 \pm 1207.4$ & \\
\hline \multirow{4}{*}{ Endometrial thickness } & Median & 8.1 & 8.85 & \multirow{4}{*}{0.7} \\
\hline & Min & 1 & 3.1 & \\
\hline & Max & 96 & 15 & \\
\hline & mean \pm SD & $9.82 \pm 8.6$ & $9.27 \pm 3.15$ & \\
\hline \multirow{4}{*}{$\begin{array}{l}\text { Intrauterine volume in } \\
\text { pregnancy }\end{array}$} & Median & 9.6 & 11.65 & \multirow{4}{*}{0.8} \\
\hline & Min & 0.3 & 0.1 & \\
\hline & Max & 270 & 108 & \\
\hline & Mean \pm SD & $23.3 \pm 37.1$ & $21.85 \pm 29.9$ & \\
\hline
\end{tabular}

\section{DISCUSSION}

In the present study, the accuracy of early ultrasound in the diagnosis of EP was increased and compared with the previous cut off point and a suitable cut off point for serum $\beta$-hCG was suggested in the possible diagnosis of ectopic pregnancy by transvaginal ultrasound in this study. Median serum $\beta$-hCG levels were significantly lower in patients who did not have ectopic pregnancy incorrect ultrasound than in those who had a correct 
diagnosis. Also, the median and time interval of LMP in patients who did not diagnose ectopic pregnancy incorrectly were significantly higher than those in whom with correct diagnosis. These two variables were not significantly correlated with each other and each of them had an independent role. The best cut off point for serum $\beta$-hCG was $105.65 \mathrm{mmol} / \mathrm{ml}$ with $83 \%$ sensitivity and $27 \%$ specificity. In the study of Samani G et al, the best cut off point was considered to be $326 \mathrm{mmol} / \mathrm{ml}$ with $86.6 \%$ sensitivity and $87.5 \%$ specificity. ${ }^{5}$

Table 3: Clinical characteristics of samples by EP.

\begin{tabular}{|l|lll|l|l|}
\hline \multirow{2}{*}{ Variables } & \multirow{2}{*}{ Levels } & \multicolumn{2}{c|}{ Undiagnosed EP } & \multicolumn{2}{l|}{ Diagnosed EP } \\
\cline { 3 - 6 } & Stomach-ache & 107 & 61.5 & 21 & 63.6 \\
\cline { 2 - 6 } Type of clinical symptom & Vaginal bleeding & 47 & 27 & 10 & 30.3 \\
\cline { 2 - 6 } & Amenorrhea & 8 & 11.5 & 2 & 6.1 \\
\hline \multirow{2}{*}{ Heterotopic pregnancy } & + & 8 & 4.6 & 0 & 0 \\
\hline \multirow{2}{*}{ Deal to surgery } & - & 166 & 95.4 & 33 & 100 \\
\hline \multirow{5}{*}{ Type of pelvic surgery } & + & 70 & 40.2 & 1 & 3 \\
\cline { 2 - 6 } & - & 104 & 59.8 & 32 & 97 \\
& Appendectomy & 6 & 9 & 0 & 0 \\
\cline { 2 - 6 } & Salpingectomy & 5 & 7.6 & 0 & 0 \\
\cline { 2 - 6 } & Caesarean & 44 & 66.7 & 8 & 67 \\
\cline { 2 - 6 } & Laparoscopy & 4 & 6.1 & 0 & 0 \\
\cline { 2 - 6 } & Curettage & 6 & 9 & 4 & 33 \\
\cline { 2 - 6 } & Other surgeries & 1 & 1.5 & 0 & 0 \\
\hline
\end{tabular}

Table 4: The finding of sonography among diagnosed EP cases.

\begin{tabular}{|c|c|c|c|}
\hline \multirow{2}{*}{ Findings } & \multirow{2}{*}{ Levels } & \multicolumn{2}{|c|}{ Diagnosed EP } \\
\hline & & n & $\%$ \\
\hline \multirow{4}{*}{ Ultrasound view of EP } & None & 0 & 0 \\
\hline & Adenexal mass & 163 & 93.7 \\
\hline & Fetus without heart rate & 8 & 4.6 \\
\hline & Fetus with heart rate & 3 & 1.7 \\
\hline \multirow{3}{*}{ Side of EP } & Without side & 2 & 1.2 \\
\hline & Right adnexal & 89 & 51.4 \\
\hline & Left adnexal & 82 & 47.4 \\
\hline \multirow{4}{*}{ Rate of free fluid } & None & 43 & 24.7 \\
\hline & A few & 99 & 56.9 \\
\hline & Moderate & 21 & 12.1 \\
\hline & More & 11 & 6.3 \\
\hline
\end{tabular}

Also given the high level of EP detected $(54.5 \%)$ in the $\beta$ hCG serum level less than $1000 \mathrm{mmol} / \mathrm{ml}$ it can be said that both cut off points in the present study and the Ghatresani study can be used as the decision criterion but due to the high variance of $\beta$-hCG values between the different sample not all of the studies can reach a definite value. So, it is not possible to determine an absolute amount of $\beta$-hCG level to detect EP and ultrasound and clinical findings along with serial evaluation of $\beta$-hCG levels may be more effective. ${ }^{5}$

In a study of 84 women with early pregnancy problems, Nayberg et al reported 3 cases $(33.3 \%)$ of 9 abnormal pregnancies with a serum $\beta$-hCG level of less than 1000 $\mathrm{mmol} / \mathrm{ml}$. In the study of Coaxiator et al, 200 patients with serum hCG - $\beta$ levels less than $1000 \mathrm{mmol} / \mathrm{ml}$ underwent transvaginal ultrasound and based on the results of this study, 21 out of 23 abnormal pregnancies were diagnosed with this method. In the present study of the total EP cases diagnosed with vaginal ultrasound, 18 $(54.5 \%)$ had $\beta$-hCG less than $1000 \mathrm{mmol} / \mathrm{ml}$ which is $33.3 \%$ higher than that of Nayberg et al with $54.5 \%$ but less than Coaxiator et al with $91.3 \% .^{6-8}$

Along with the present study and the Ghatresani study, results showed that ultrasound observation of gestational sac increased with increasing gestational age and serum $\beta$-hCG level. Based on the results of this study, gestational sac should be observed if transvaginal ultrasound is used at levels of $\beta$-hCG above 1500 to 1800 
$\mathrm{mmol} / \mathrm{ml}$ in single pregnancy and above $2300 \mathrm{mmol} / \mathrm{ml}$. Otherwise an ectopic pregnancy or a recent abortion will be considered. ${ }^{5}$ In another study by Dart et al, it was shown that transvaginal ultrasound in cases with serum $\beta$ hCG levels less than $1000 \mathrm{mmol} / \mathrm{ml}$ could be helpful in the diagnosis of ectopic pregnancy. In this retrospective study, 128 patients with positive serum $\beta$-hCG but less than $1000 \mathrm{mmol} / \mathrm{ml}$ underwent transvaginal ultrasound within 24 hours of serum hCG- $\beta$ measurement. Finally about one third of patients with ectopic pregnancy were diagnosed by transvaginal ultrasound of them, 5 patients $(20.3 \%)$ had a serum $\beta-\mathrm{hCG}$ level of less than $500 \mathrm{mmol} /$ ml. ${ }^{9}$ The findings of these studies are in contradiction with the appropriate cross section of serum hCG- $\beta$ for the efficacy of transvaginal ultrasound in the diagnosis of ectopic pregnancy with the results of the present studies and the Ghatresani. Diagnostic accuracy of transvaginal ultrasound in the present study and Ghatresani study was much higher than above studies in lower serum $\beta$-hCG levels which could be related to the time of doing this study in compare to other studies. ${ }^{5}$ In the study of Creek et al, it was shown that in patients referred to the emergency for one time up to $90 \%$ of intrauterine pregnancies and up to $75 \%$ of ectopic pregnancies can be diagnosed. ${ }^{10}$

In Key S et al study on 337 EP cases in India, concluded that determine an amount of $\beta$-hCG levels could not be determined for EP diagnosis and suggested the simultaneous evaluation of sonographic and clinical findings. ${ }^{11}$ In a prospective study on 35 pregnant women referred to the emergency by Simsec et al in Turkey, they were studied in addition to demographic parameters, $\beta$ hCG level, transvaginal ultrasound pathology findings and treatment protocol and results indicated that the level of $\beta$-hCG alone was not valuable in the diagnosis of ruptured EP and the final diagnosis should still be with transvaginal ultrasound surgery and ultrasound. ${ }^{12}$ Heather Murray et al in a study stated that advances in ultrasound technology and $\beta$-hCG measurement methods have complicated the diagnostic workup process in patients with suspected EP because less invasive treatment options are being developed. ${ }^{13}$ In a study by Conolly et al by examining symptomatic first trimester pregnant women (abdominal pain and vaginal bleeding) by transvaginal ultrasound and $\beta$-hCG measurement they concluded that improved intrauterine pregnancy detection with lower $\beta$-hCG could be improved by ultrasound technology however the cut of area is higher than the current guidelines. ${ }^{14}$ In the study of Adhikari et al, the efficacy of transvaginal ultrasound in the diagnosis of ectopic pregnancy was evaluated in 74 patients and it was concluded that due to the wide range of $\beta$-hCG in ectopic pregnancies with and without live embryos if the patient is symptomatic and serum $\beta$-hCG levels lower than recommended by previous studies should not be ruled out the ultrasound. ${ }^{15}$ In the study of Wang et al it was concluded that considering the cut-off point of 3000 $\mathrm{mm} / \mathrm{ml}$ may not be helpful in the diagnosis of ectopic pregnancy using ultrasound. ${ }^{16}$ In a study by Korvar et al, it was concluded that unlike the former, it is believed that the association of ultrasound with serum $\beta$-hCG levels in the diagnosis of normal and ectopic pregnancy would not produce favorable results. ${ }^{17}$ In a study by Jey B et al on the 215 cases of EP it was concluded that improvement of the ultrasound procedures in the diagnosis of EP reduced the incidence of false negative about $6 \%$ to $13 \%$ in laparoscopy. ${ }^{18}$ It can be said that these conclusions have been resulted advances during both in the determination of serum $\beta$-hCG levels and in the diagnostic accuracy of ultrasound devices in recent years. ${ }^{19-20}$

\section{CONCLUSION}

Due to the lack of a new study in this field as well as the existence of different inconsistencies in the amount of $\beta$ hCG and the value of vaginal ultrasound in the diagnosis of EP, the present study was designed to add new scientific evidence. It can be argued that the small sample size in the group with non-diagnostic ultrasound results may affect the current study's ability to determine the appropriate cut off point for $\beta$-hCG despite achieving acceptable sensitivity and specificity because different sources have indicated different cut off points for $\beta-\mathrm{hCG}$ serum levels in the diagnosis of EP each in turn has strengths and weaknesses and may be due to different results due to differences in $\beta$-hCG measurement methods. Therefore, further studies with higher sample size are recommended for definitive results. It can also be said that it is not possible to determine an absolute amount of $\beta$-hCG levels for EP detection and ultrasound and clinical findings along with serial evaluation of $\beta$ hCG levels may be more effective in the future.

\section{Funding: No funding sources \\ Conflict of interest: None declared}

Ethical approval: The study was approved by the Institutional Ethics Committee

\section{REFERENCES}

1. Mc Ghan JP, Goldberg BB. Diagnostic ultrasound. CRC Press; $2^{\text {nd }}$ edition. 2008:1046-1047.

2. Dialani V, Levine D. Ectopic pregnancy: a review. Ultrasound Q. 2004;20(3):105-17.

3. Bree RL, Edwards M, Böhm-Vélez M, Beyler S, Roberts J, Mendelson EB. Transvaginal sonography in the evaluation of normal early pregnancy: correlation with HCG level. AJR Am J Roentgenol. 1989;153(1):75-9.

4. Nyberg DA, Laing FC, Filly RA, Zarutskie PW. Ultrasonographic differentiation of the gestational sac with quantitative HCG levels. J Ultrasound Med. 1987;6:145.

5. Ghatrehsani F, Nourian A, Farzadi L. Transvaginal ultrasound compared with serum $\beta$-hCG level for diagnosis of ectopic pregnancy in symptomatic patients. J Arak Uni Med Sci. 2018;20(10):90-100.

6. Nyberg DA, Mack LA, Laing F, Jeffrey RB. Early pregnancy complications: endovaginal sonographic 
findings correlated with humanchorionic gonadotropin levels. Radiol. 1988;167(3):619-22.

7. Cacciatore B, Stenman UH, Ylöstalo P. Diagnosis of ectopic pregnancy by vaginal ultrasonography in combination with adiscriminatory serum hCG level of 1000 IU/1(IRP). Int J Obstet Gynaecol. 1990;97(10):904-8.

8. Fleischer A, Pennell R, McKee M, Worrell J, Keefe B, Herbert C, et al. Ectopic pregnancy: features at transvaginal sonography. Radiol. 1990;174(2):375-8.

9. Dart RG, Kaplan B, Cox C. Transvaginal ultrasound in patients with low $\beta$-human chorionic gonadotropin values: How often is thestudy diagnostic? Ann Emerge Med. 1997;30(2):135-40.

10. Kirk E, Papageorghiou AT, Condous G, Tan L, Bora $\mathrm{S}$, Bourne $\mathrm{T}$. The diagnostic effectiveness of an initial transvaginal scan in detecting ectopic pregnancy. Human Reprod. 2007;22(11):2824-8.

11. Surampudi K, Gundabattula SR. The role of serum beta hCG in early diagnosis and management strategy of ectopic pregnancy. J Clin Diagnos Res. 2016;10(7):QC08.

12. Simsek Y, Ay MO. Analysis of ectopic pregnancies admitted to emergency department. Turkish J Emerg Med. 2015;15(4):151-4.

13. Murray H, Baakdah H, Bardell $\mathrm{T}$, Tulandi $\mathrm{T}$. Diagnosis and treatment of ectopic pregnancy. Canadian Med Assoc J. 2005;173(8):905-12.

14. Connolly A, Ryan DH, Stuebe AM, Wolfe HM. Reevaluation of discriminatory and threshold levels for serum $\beta$-hCG in early pregnancy. Obstet Gynecol. 2013;121(1):65-70.

15. Adhikari S, Blaivas M, Lyon M. Diagnosis and management of ectopic pregnancy using bedside transvaginal ultrasonography in the ED: a2-year experience. The Am J Emerg Med. 2007;25(6):591-6.

16. Wang R, Reynolds TA, West HH, Ravikumar D, Martinez C, McAlpine I, et al. Use of a $\beta$-hCG discriminatory zone with bedside pelvic ultrasonography. Ann Emerg Med. 2011;58(1):12-20.

17. Korevaar TI, Steegers EA, de Rijke YB, Schalekamp-Timmermans S, Visser WE, Hofman A, et al. Reference ranges and determinants of total hCG levels during pregnancy: the generation $\mathrm{R}$ study. Eur J Epidemiol. 2015;30(9):1057-66.

18. Berry J, Davey M, Hon MS, Behrens R. Optimizing the diagnosis of ectopic pregnancy. Journal of obstetrics and gynaecology. J Institute Obstet Gynaecol. 2016;36(4):437-9.

19. Greene DN, Grenache DG. Pathology consultation on human chorionic gonadotropin testing for pregnancy assessment. Am J Clin Pathol. 2015;144(6):830-6.

20. Desai D, Lu J, Wyness SP, Greene DN, Olson KN, Wiley CL, et al. Human chorionic gonadotropin discriminatory zone in ectopic pregnancy: does assay harmonization matter? Fertil Steril. 2014;101(6):1671-4.

Cite this article as: Zeynizadeh-Jeddi S, Mobaraki N, Pirzadeh A. Transvaginal ultrasound compared with serum $\beta$-hCG level for diagnosis of ectopic pregnancy in symptomatic patients. Int J Reprod Contracept Obstet Gynecol 2020;9:1228-33. 